\title{
Ethical use of covert videoing techniques in detecting Munchausen syndrome by proxy
}

\author{
D M Foreman, C Farsides
}

\begin{abstract}
Munchausen syndrome by proxy is an especially malignant form of child abuse in which the carer (usually the mother) fabricates or exacerbates illness in the child to obtain medical attention. It can result in serious illness and even death of the child and it is difficult to detect. Some investigators have used video to monitor the carer's interaction with the child without obtaining consent-covert videoing. The technique presents several ethical problems, including exposure of the child to further abuse and a breach of trust between carer, child, and the professionals. Although covert videoing can be justified in restricted circumstances, new abuse procedures under the Children Act now seem to make its use unethical in most cases. Sufficient evidence should mostly be obtained from separation of the child and carer or videoing with consent to enable action to be taken to protect the child under an assessment order. If the new statutory instruments prove ineffective in Munchausen syndrome by proxy covert videoing may need to be re-evaluated.
\end{abstract}

In Munchausen syndrome by proxy a carer invents or creates symptoms in his or her charge (typically though not exclusively a child) to gain medical attention. ${ }^{1}$ For example, a mother may suffocate her child to mimic apnoea, ${ }^{2}$ inject insulin, ${ }^{3}$ or even drain blood to produce collapse. ${ }^{4}$ She will then obtain medical help for the child and appear to work closely with doctors in attempting to manage the problem. Some authorities recommend videoing the carer's interaction with the child without her knowledge in at least some cases. ${ }^{5-8}$ But use of covert videoing has generated a fierce debate $^{9}$ since in attempting to protect the child it infringes the rights of consent and privacy and exposes the child to further harm.

The implementation of the Children Act has raised additional issues. ${ }^{10}$ The act assigns the responsibility of investigating child abuse to the local authority. The local authority's investigation, though multidisciplinary, is closely constrained by guidelines that insist on partnership with the parents even when abuse is suspected. ${ }^{11}$ Munchausen syndrome by proxy has competing claims for ownership of the management of Munchausen syndrome by proxy.

\section{Safe use of covert videoing}

Any general justification of covert videoing must refer to the duties of both doctors and local authorities. The Children Act requires local authorities to ensure the welfare of the child and to protect the child..$^{10}$ Doctors have a similar duty to their patients. Covert video assessment is problematic because the child's safety is risked to ensure long term protection. Any defence of covert videoing must begin with the claim that, although the child is being harmed, he or she is being protected from greater harm and that there is no other way to achieve this. Munchausen syndrome by proxy can result in serious illness and even death. ${ }^{14}{ }^{15} \mathrm{It}$ is difficult to detect, ${ }^{81617}$ but covert video assessment has a sensitivity of over $90 \%$ in suitably screened cases. $^{18}$ Knowledge that a carer has Munchausen syndrome by proxy allows action to protect the child. Thus covert videoing is ethical for both doctors and local authorities if it provides information to act on that is not otherwise available.

One objection to covert videoing is that "information to act on" is not the same as certainty. If a doctor is sufficiently confident that someone has Munchausen syndrome by proxy then allowing an additional event to prove this does harm without any useful gain in knowledge, which is unethical. ${ }^{19} 20$ Proof can be obtained by less contentious investigations, such as careful interviewing of multiple informants or a trial of physical separation between carer and child. ${ }^{17}$ As these methods present less risk to the child, covert videoing can be ethical only if they fail to provide sufficient evidence. It cannot be substituted for them.

\section{When no proof is found}

Covert videoing infringes the rights of those observed in privacy, honesty, and autonomy. If Munchausen syndrome by proxy is detected by using video the benefit to the child substantially outweighs the damage caused by these infringements. But what if the syndrome is not found? Godding and Kruth described cases in which carers did not respond appropriately to their child's asthma. ${ }^{21}$ Munchausen syndrome by proxy was diagnosed on the basis of assessment of carer's intentions. Covert video, which records actions, would not be suitable in such cases. Other technical difficulties can reduce certainty in video evidence-for example, the camera may not record the whole room. ${ }^{6}$

Unfounded investigations of abuse can cause family stress, breakup, and loss of earnings. ${ }^{22}$ Parents also might withdraw their children from necessary medical investigations because they lose trust in the doctor. It is therefore essential to have good reasons to suspect Munchausen syndrome by proxy before using covert

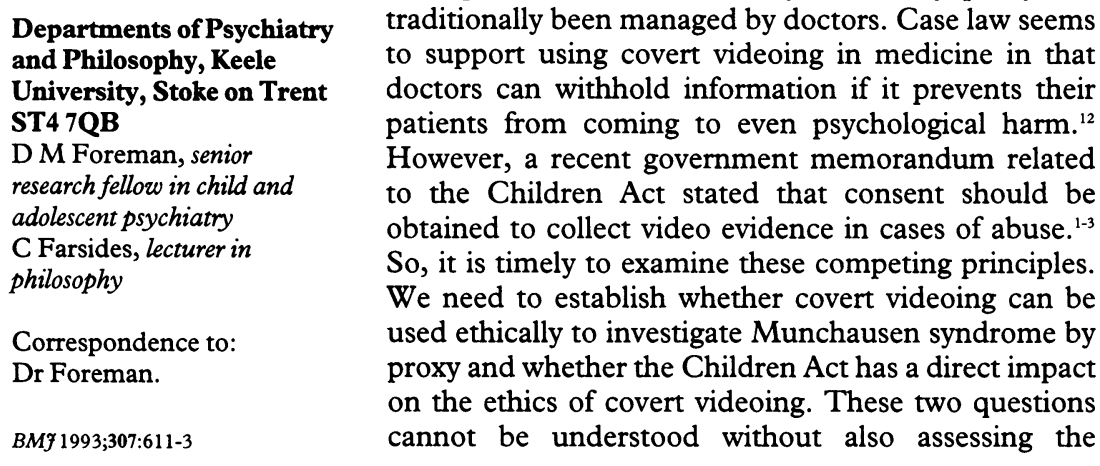

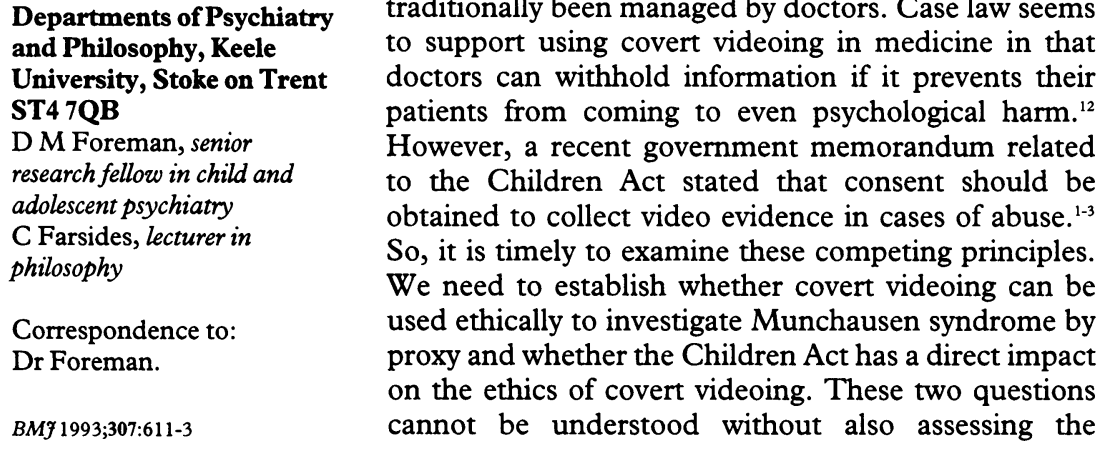

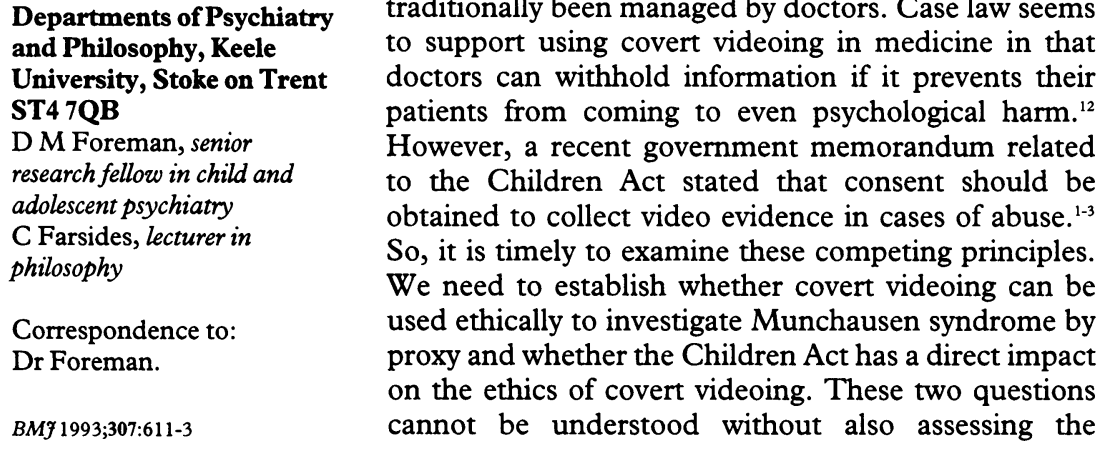

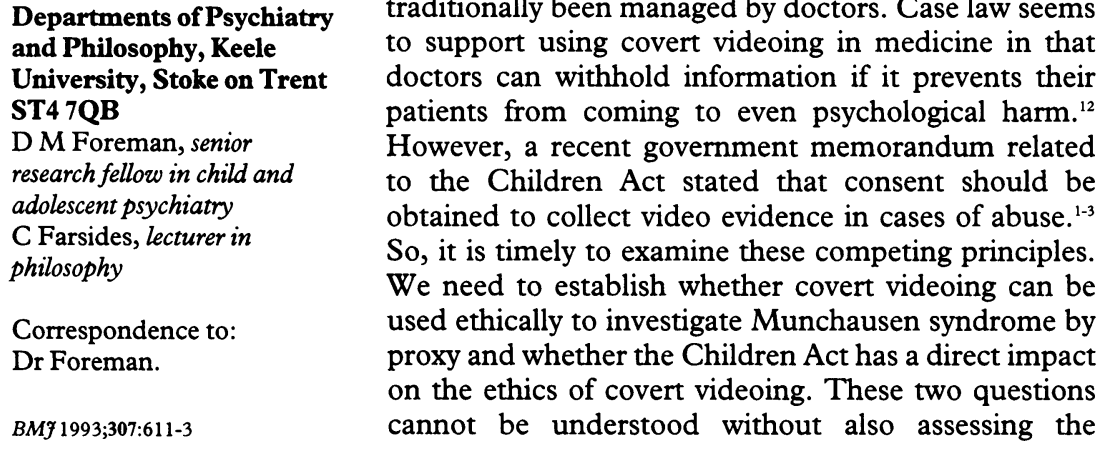

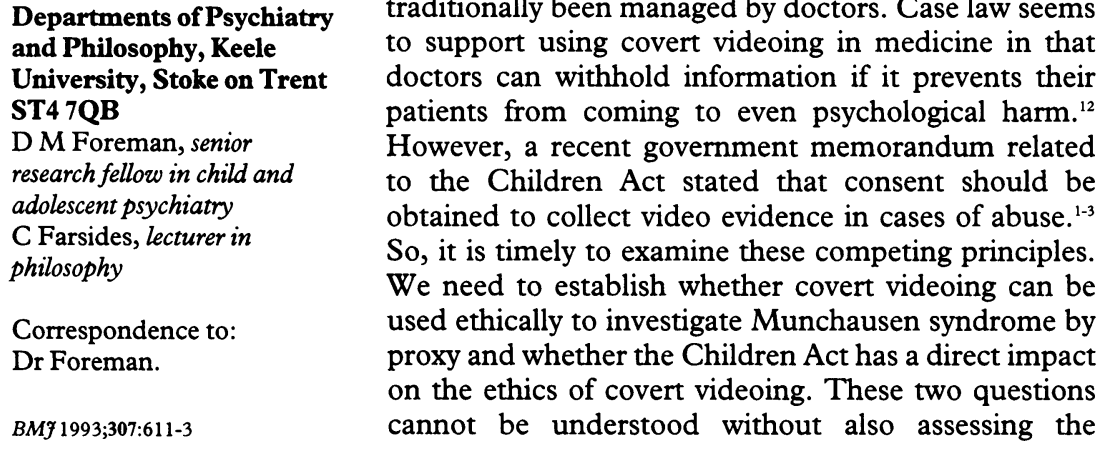

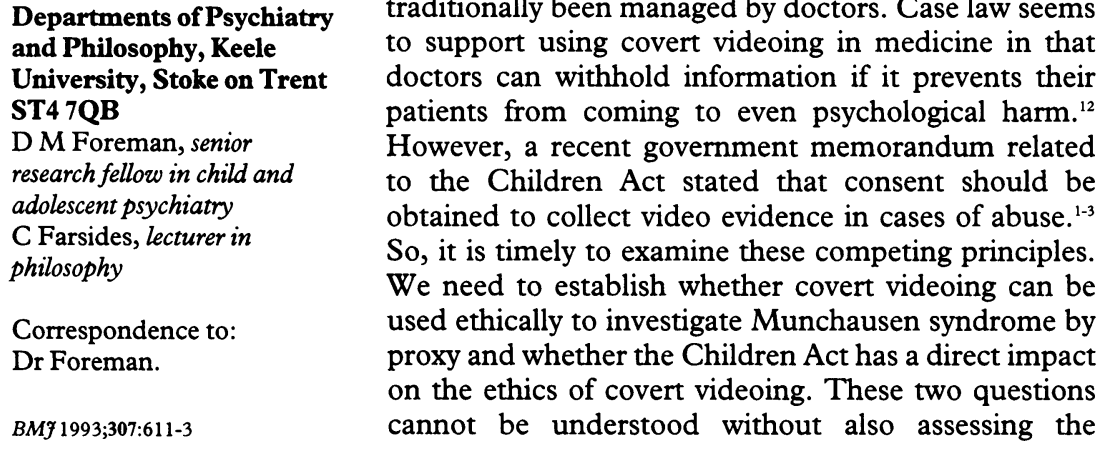

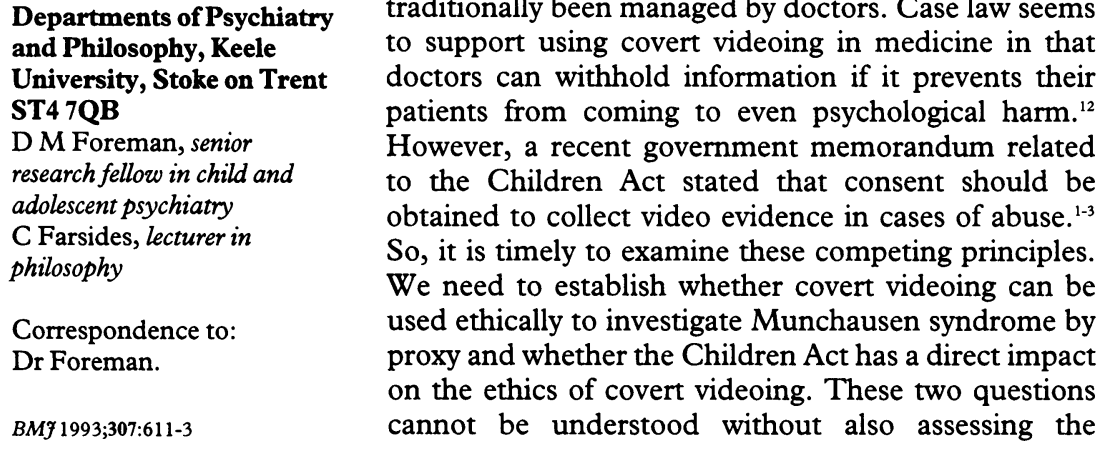

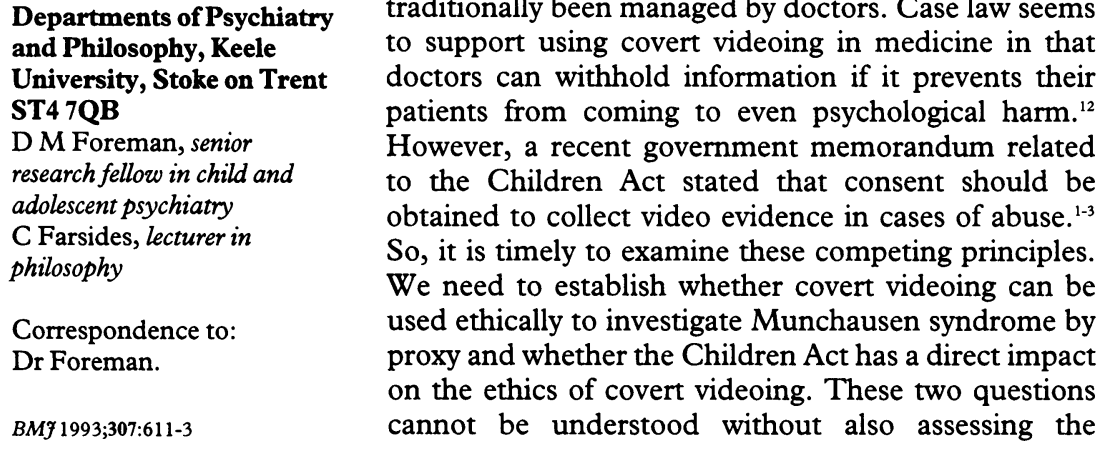

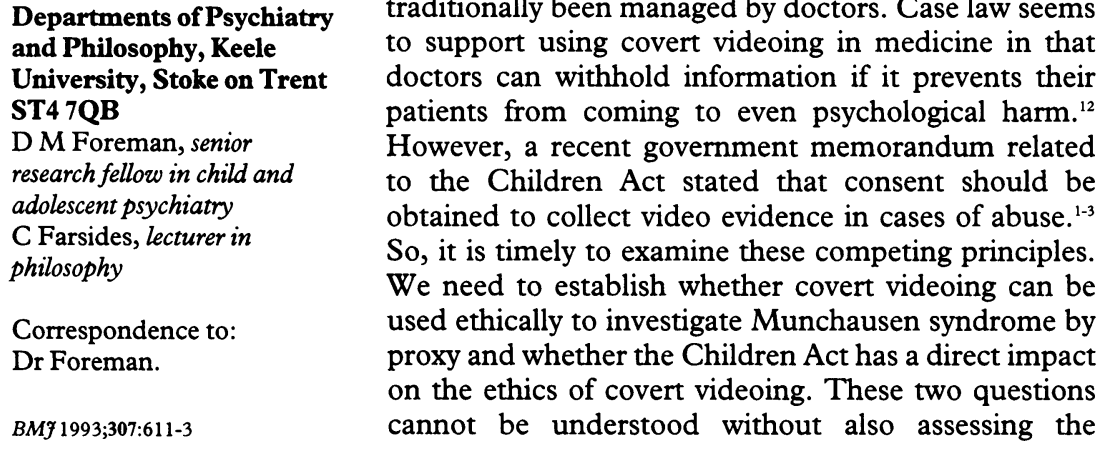

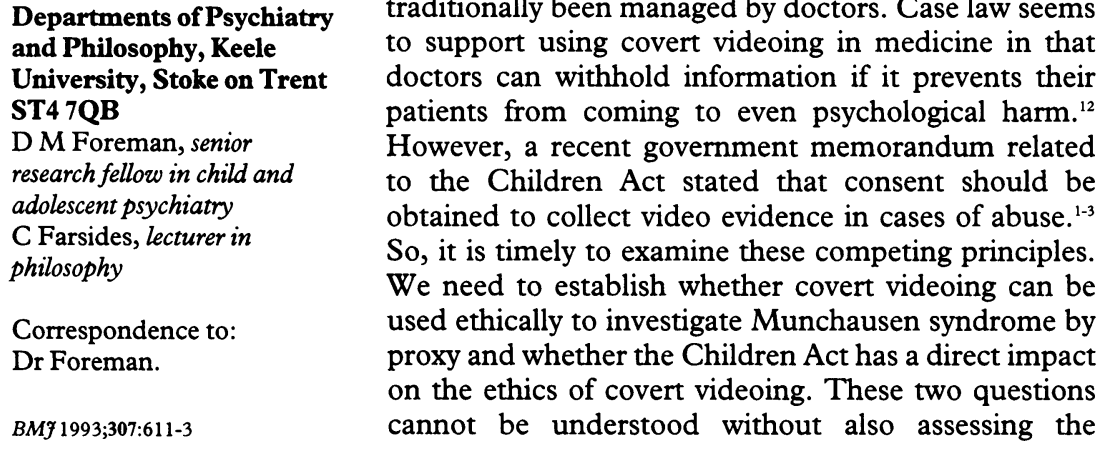

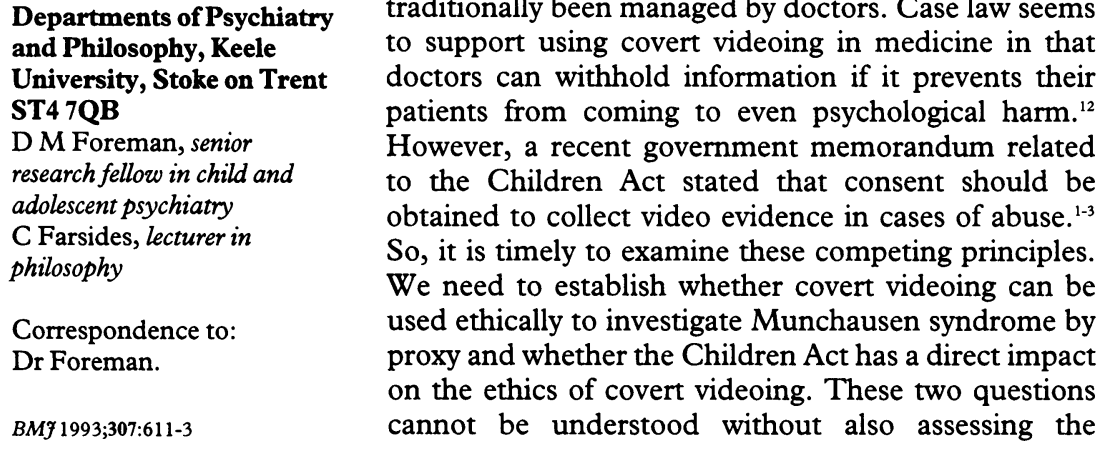

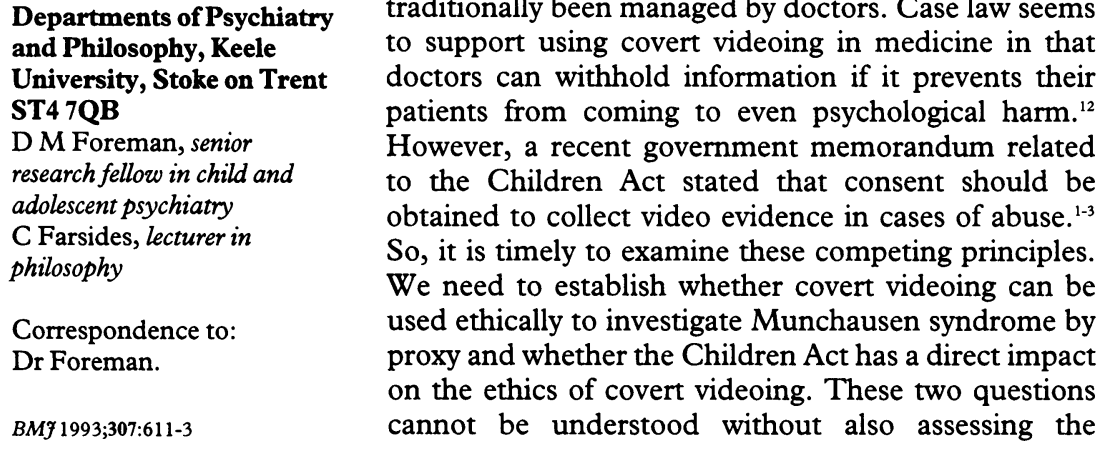

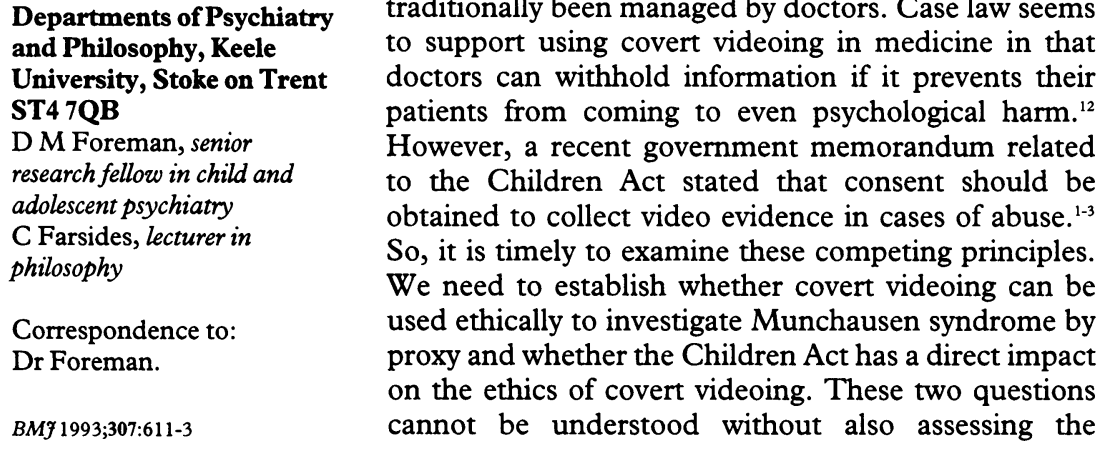

$\begin{array}{ll}\begin{array}{l}\text { Departments of Psychiatry } \\ \text { and Philosophy, Keele }\end{array} & \begin{array}{l}\text { traditionally been managed by doctors. Case law seems } \\ \text { to support using covert videoing in medicine in that } \\ \text { University, Stoke on Trent }\end{array} \\ \begin{array}{l}\text { doctors can withhold information if it prevents their } \\ \text { patients from coming to even psychological harm. }\end{array} \\ \begin{array}{l}\text { D M Foreman, senior } \\ \text { research fellow in child and }\end{array} & \begin{array}{l}\text { However, a recent government memorandum related } \\ \text { to the Children Act stated that consent should be } \\ \text { adolescent psychiatry }\end{array} \\ \begin{array}{ll}\text { C Farsides, lecturer in } & \text { So, it is timely to examine these competing principles. } \\ \text { philosophy } & \text { We need to establish whether covert videoing can be } \\ \text { Correspondence to: } & \text { used ethically to investigate Munchausen syndrome by } \\ \text { Dr Foreman. } & \text { proxy and whether the Children Act has a direct impact } \\ \text { on the ethics of covert videoing. These two questions }\end{array} \\ B M \Im 1993 ; 307: 611-3 & \text { cannot be understood without also assessing the }\end{array}$

$\begin{array}{ll}\begin{array}{l}\text { Departments of Psychiatry } \\ \text { and Philosophy, Keele }\end{array} & \begin{array}{l}\text { traditionally been managed by doctors. Case law seems } \\ \text { to support using covert videoing in medicine in that } \\ \text { University, Stoke on Trent }\end{array} \\ \begin{array}{l}\text { doctors can withhold information if it prevents their } \\ \text { patients from coming to even psychological harm. }\end{array} \\ \begin{array}{l}\text { D M Foreman, senior } \\ \text { research fellow in child and }\end{array} & \begin{array}{l}\text { However, a recent government memorandum related } \\ \text { to the Children Act stated that consent should be } \\ \text { adolescent psychiatry }\end{array} \\ \begin{array}{ll}\text { C Farsides, lecturer in } & \text { So, it is timely to examine these competing principles. } \\ \text { philosophy } & \text { We need to establish whether covert videoing can be } \\ \text { Correspondence to: } & \text { used ethically to investigate Munchausen syndrome by } \\ \text { Dr Foreman. } & \text { proxy and whether the Children Act has a direct impact } \\ \text { on the ethics of covert videoing. These two questions }\end{array} \\ B M \Im 1993 ; 307: 611-3 & \text { cannot be understood without also assessing the }\end{array}$ 
videoing, one of which must be a reasonable suspicion that an illness is factitious. To be reasonable, the suspicion must be based on good medical knowledge, so should be raised by a doctor. Equally, the investigation must be performed by someone qualified to undertake it-also a doctor. Should doctors therefore continue to manage the syndrome medically despite the Children Act?

\section{Social or medical problem?}

A diagnosis of Munchausen syndrome by proxy indicates that the child is unwell because of harm, not sickness. This implies social rather than medical remedies, with the emphasis on protecting the child. Some reports suggest that doctors have difficulty in managing protection from, as opposed to investigation of, the condition. The medical treatment, ${ }^{23}$ and perhaps even medical staff, ${ }^{24}$ may unwittingly contribute to the aetiology of the abuse. Issues of team cohesion that are fundamental to child protection ${ }^{25}$ can be devalued in a medical setting. In their description of a child's death while a parent was being investigated by a paediatric team for Munchausen syndrome by proxy, Sugar et al did not consider that the team's disagreement about the likelihood of abuse had impaired the management because all agreed that investigation was necessary. ${ }^{26}$ Clearly, such disagreement would affect any decision to protect a child.

Covert video infringes rights and causes harm but teams may use it instead of safer investigations such as separation or multiple histories or to resolve staff conflict. ${ }^{5-7}$ Such use may not be justified, and it would be desirable to transfer responsibility to local authorities provided that doctors are not hampered in their investigations. The Children Act requires just such a relationship between local authorities and doctors, suggesting that such a transfer is practicable. ${ }^{11}$

\section{Implications of Children Act}

If Munchausen syndrome by proxy is best managed by the local authority then it is reasonable to review the impact the Children Act has on covert videoing. The technique is ethical for a local authority only if other safer investigations cannot provide sufficient evidence. Remarkably, the assessment order of the Children Act may have made covert videoing unnecessary. ${ }^{10}$ The order is intended to ensure that abusing carers do not avoid detection by refusing investigations; a purpose identical to that of covert video. The order can be implemented if there is "reasonable suspicion"-the same criterion necessary for covert video. It does not preclude the use of video, but its use will be overt. However, the act requires different information to be collected. It seeks to establish whether a child is at risk of significant harm and therefore in need of protection. ${ }^{11}$ The identity of the perpetrator and how the harm is inflicted are only important to the extent that they assist protection of the child.

The impact of this difference in emphasis can be seen by comparing covert video with temporary separation as detectors of Munchausen syndrome by proxy. Separation is intrinsically safer, in that an improvement is looked for rather than a further exacerbation. It is honest and can be done as part of a partnering relationship with the carer as the doctor does not have to suggest that the carer might maliciously harm the victim. It can never provide the same level of certainty as covert videoing in showing agents and actions, but it can establish whether a carer is more likely to be harmful to a child than not. The Children Act is civil legislation and only a "balance of probabilities" is needed to use its instruments of protection. ${ }^{11}$ So, in cases where either covert video or separation are indicated as investigations "information to act on" can now be provided by separation under an assessment order, rendering covert video redundant The government recommends that although criminal prosecution is desirable it is not always possible since the first priority is the welfare of the child. ${ }^{11}$ Thus, covert videoing should not be used solely to detect crime.

Are there cases of Munchausen syndrome by proxy in which covert videoing is indicated but separation is not? Cases in which the abuser belongs to the staff ${ }^{27}$ or the harm caused by long acting drugs ${ }^{28}$ will be difficult to detect with covert videoing. Also, older children may collude with their mothers in maintaining the factitious disorder. ${ }^{29} 30$ Separation will not be an adequate investigation of this, as the child might maintain the symptoms and signs in the absence of the mother. Overt video under an assessment order, as mentioned above, may be useful as it will either record the fabrication or deter it. In either case the outcome will be sufficiently suggestive of Munchausen syndrome by proxy to enable action on, at least, the balance of probabilities.

\section{Conclusions}

The use of covert videoing in Munchausen syndrome by proxy, while controversial, is ethical in restricted circumstances. Current management of Munchausen syndrome by proxy, including covert videoing, would benefit from a change in emphasis. The first intention should be to protect the child, and only then should diagnosis be attempted. Social workers should have a bigger role in assessment of possible Munchausen syndrome by proxy. The framework of the 1989 Children Act seems well suited to the management of Munchausen syndrome by proxy, particularly the assessment order. Use of the order holds the promise of making covert videoing redundant, although it has not yet been used in this situation.

1 Meadow R. Munchausen syndrome by proxy. The hinterland of child abuse. Lancet 1977;ii:343-5.

2 Rosen C, Frost J, Glaze D. Child abuse and recurrent infant apnea. 9 Pediatrics 1986;109:1065-7.

3 Bauman W, Yalow R. Child abuse: parenteral insulin administration. I Pediatrics 1981;99:588-91.

4 Clark G, Key J, Rutherford P, Bithoney W. Munchausen's syndrome by proxy (child abuse) presenting as apparent autoerythrocyte sensitisation syndrome: an unusual presentation of Polle syndrome. Pediatrics 1984;74:1100-2.

5 Rosen C, Frost J, Brickner T, Tarnow J, Gillette P, Dunlavy S. Two siblings with recurrent cardiorespiratory arrest: Munchausen syndrome by proxy or child abuse? Pediatrics 1983;71:715-20.

6 Epstein M, Markowitz R, Gallo D, Holmes J, Gryboski J. Munchausen syndrome by proxy: considerations in diagnosis and confirmation by video syndrome by proxy: considerations in
surveillance. Pediatrics 1987;80:220-4.

7 Southall D, Stebbens V, Rees S, Lang M, Wamer J, Shinebourne E. Apnoeic episodes induced by smothering: two cases identified by covert video surveillance. $B M \mathcal{F}$ 1987;294:1637-41.

8 Southall D, Samuels M. Munchausen syndrome by proxy. $\operatorname{Br} \mathcal{F}$ Hosp Med 1992;47:759-62.

9 Williams C, Bevan V. The secret observation of children in hospital. Lancet 1988;: $: 780-1$.

10 Children Act. London: HMSO, 1989.

11 Home Office, Department of Health, Department of Education and Science, Welsh Office. Working together (under the Children Act 1989). London: HMSO, 1991.

12 Mason J, McCall Smith A. Law and medical ethics. London: Butterworths, 1991:242-52.

13 Home Office, Department of Health. Memorandum of good practice on video recorded interviews with child witnesses for criminal proceedings. London: HMSO, 1992.

14 Meadow R Munchausen syndrome by proxy. Arch Dis Child 1982;57:92-8.

15 Bools C, Neale B, Meadow S. Co-morbidity associated with fabricated illness (Munchausen syndrome by proxy). Arch Dis Child 1992;67:77-9.

16 Turk L, Hanrahan K, Weber E. Munchausen syndrome by proxy: a nursing overview. Compehensive Pediatric Nursing 1990;13:279-88.

17 Leonard K, Farrell P. Munchausen's syndrome by proxy. A little-known type of abuse. Postgrad Med 1992;91:197-204.

18 Samuels M, McClaughlin W, Jacobson R, Poets C, Southall D. Fourteen cases of imposed upper airway obstruction. Arch Dis Child 1992;67:162-70.

19 Lanman J, Guy L, Daneis J. Retrolental fibroplasia and oxygen therapy. 7AMA 1954;155:223-6.

20 Campbell A. Moral dilemmas in medicine. 2nd ed. Edinburgh: Churchill Livingstone, 1975 .

21 Godding V, Kruth $M$. Compliance with treatment in asthma and Munchausen syndrome by proxy. Arch Dis Child 1991;66:956-60.

22 Schultz L. One hundred cases of unfounded child sexual abuse: a survey and recommendations. Issues in Child Abuse Accusations 1989;1:29-38. 
23 Eminson D, Postlethwaite R. Factitious illness: recognition and management. Arch Dis Child 1992;67:1510-6.

24 Sigal M, Gelkopf $M$, Meadow R. Munchausen by proxy syndrome: the triad of abuse, self-abuse, and deception. Compr Psychiatry 1989;30:527-33.

25 Department of Health and Social Security. Report of the committee of inquiry into the care and supervision provided in relation to Maria Colvell. London: HMSO, 1974:61-76.

26 Sugar J, Belfer M, Israel E, Herzog D. A 3-year-old boy's chronic diarrhea and unexplained death (clinical conference). f Am Acad Child Psychiatry 1991:30:1015-21.
27 Former nurse committed for trial accused of murdering four children and attempting to murder another nine. Times 1992;March 12:20.5b.

28 Rosenberg D. Web of deceit: a literature review of Munchausen syndrome by proxy. Child Abuse Negl 1987;11:547-63.

29 Bhugra D. Psychiatric Munchausen's syndrome. Acta Psychiatr Scand 1988;77:497-503.

30 Asher R. Munchausen syndrome. Lancet 1951;i:339-41.

\title{
Ethical use of covert videoing for potentially life threatening child abuse: a response to Drs Foreman and Farsides
}

\author{
David P Southall, Martin P Samuels
}

Foreman and Farsides suggest that the Children Act 1989 provides sufficient ways of protecting children from abuse without the need for covert video surveillance. To our knowledge, the intentional suffocation and poisoning of children by parents are the only forms of child abuse in which covert videoing has been reported. ${ }^{1-3}$ We will focus on its use in suffocation.

Intentional suffocation presents as recurrent cyanotic-apnoeic episodes of unknown cause in infants and young children. Such events can result in recurrent loss of consciousness, cerebral injury, lung injury (personal observations), or sudden death. ${ }^{4}$ Foreman and Farsides argue that covert videoing may be an inappropriate investigation for such events because the technique is incompatible with the Children Act; it sets the child up for further abuse in order to make the diagnosis; it involves a breach of confidentiality and trust between the paediatrician, social worker, nurses, and parent; and it can be replaced by an assessment order with overt video surveillance.

\section{Validity under Children Act}

We do not agree that covert videoing is incompatible with the Children Act, which states as its primary objective the welfare of the child. Although the argument about balance of probability within the act is clear, it is incumbent on all agencies working together on cases of suspected suffocation to obtain the most objective and definitive information to ensure the best protection of the child. Uncertainty arising from insufficient information could lead to sudden death, cerebral injury, or long term hidden emotional and physical torment that the child and his or her siblings have little or no defence against. ${ }^{5}$

Foreman and Farsides argue that involvement of doctors rather than the local authority in diagnosing this form of abuse is not always appropriate and could be harmful. We agree with this and consider that all groups must work together. Before starting covert videoing, a multidisciplinary strategy meeting should be convened by a senior social worker to consider the information that exists about the child and family. At this meeting paediatric medical and nursing staff, social workers, police officers, and legal representatives can discuss whether there is sufficient "information to act on" concerning the diagnosis of suffocation. Covert videoing would be used only where it is felt that the diagnosis is sufficiently uncertain and the child will not be protected in the long run.

The courts generally welcome the evidence obtained by covert videoing as it is usually definitive and cases are uncontested. This thereby reserves limited resources, both in time and in funding, for other children requiring help under the Children Act (one of its main principles is to avoid delay).

\section{The need for further abuse to make the diagnosis}

Although covert videoing requires further abuse to establish the diagnosis, this abuse is taking place in hospital under continuous surveillance and should be intercepted early. Observers can alert nursing staff to intervene as soon as suffocation has begun (usually a maximum of 25 seconds). ${ }^{6}$ Loss of consciousness occurs after 60-80 seconds and episodes of suffocation at home may last for 2-4 minutes (based on physiological recordings). Thus the risk of an "observed" episode is almost certainly less than that of returning a child to a parent because of insufficient information about the cause of the cyanotic-apnoeic events.

Provided that appropriate guidelines and standards are established, it should be possible to minimise the risk during covert videoing. This can be achieved by establishing a protocol in conjunction with the social services department, the police, and the area child protection team. Such a protocol should ensure that the child is in constant view; that a foolproof system exists for communicating between observers and the ward nurse responsible for intervention; that the child's oxygenation is monitored and alarms can be heard by the observers; and that observers are properly trained, with instruction in the use of video technology, a review of previously recorded events, and one to one discussion with the paediatrician in charge.

Other unexpected forms of abuse with immediately damaging effects, such as fractures, may not be (and have not been) prevented by the above guidelines. Without the information that covert videoing provides, however, there may be insufficient information to protect the child in the long term, with the result that such injuries happen later at home. Nevertheless, every attempt must be made to minimise the potential for further abuse during covert videoing.

\section{Breach of trust}

The breach of trust between paediatrician, social worker, nurse, and parent is regrettable but, in our view, if a parent may be inflicting life threatening abuse on his or her child this becomes justifiable. ${ }^{7}$ The professional's duty is to the child first and to the parents second, recognising that the child lives within the family.

Any protocol that uses covert videoing must ensure that it is the child and not the parent who is under observation at all times. As suffocation is generally a problem in infants and preschool children they are unlikely to suffer embarrassment. Foreman and Farsides raised the potential for problems associated with a failure to detect abuse with covert videoing. This is uncommon: 3 out of 28 cases in one centre's experience. In one of the three cases abnormal interactions between the parent and child were observed whenever the parent thought she was alone.
Correspondence to:

BMY 1993;307:613-4 